\title{
Macroeconomia
}

\section{Breve nota sobre regime de metas de inflação e crescimento econômico}

Norberto Montani Martins*

Resumo: O crescimento econômico brasileiro na história recente é, no mínimo, decepcionante: nos últimos anos, o Brasil cresceu menos que o mundo e que as economias emergentes, em geral. A reestruturação do arcabouço de política econômica em 1999, pautada, dentre outras medidas, na adoção da sistemática de metas para inflação, não logrou romper a trajetória de baixo crescimento da economia brasileira. Pelo contrário, o novo regime apenas reforçou o resultado agonizante do país segundo esta métrica. Nesse contexto, o artigo tem por objetivo analisar se o fraco desempenho brasileiro é um caso particular ou se a implementação do regime de metas para inflação, genericamente, pode ser associada a resultados inferiores quanto ao crescimento, conforme a experiência de outras jurisdições.

Palavras-chave: Regime de Metas para Inflação, crescimento econômico, Brasil.

Classificação JEL: E52; E60; O50.

* Doutorando do Programa de Pós-Graduação em Economia do Instituto de Economia da UFRJ.
E-mail: norberto.martins@anbima.com.br 


\section{Introdução}

O crescimento econômico brasileiro desde a adoção do regime de metas de inflação (RMI) pode ser considerado frustrante. Via de regra, a economia brasileira cresceu a taxas inferiores em relação à economia mundial e significativamente inferiores quando confrontadas com as taxas de seus pares emergentes, como ilustrado na Tabela 1.

A decepção também deriva do fato de que o crescimento pós-1999 não rompeu o padrão anterior, marcado pela instabilidade e/ou baixo dinamismo, que vigorava desde a crise do início dos anos 1980. Ainda, conforme o levantamento histórico realizado por Gonçalves (2014), que abarca o período desde o início da República, o desempenho recente é, no máximo, classificável como "fraco" ou "medíocre".

Tabela 1 - Crescimento Real do PIB (\% a.a.)

\begin{tabular}{c|ccccccccccccccc}
\hline & $\mathbf{9 9}$ & $\mathbf{0 0}$ & $\mathbf{0 1}$ & $\mathbf{0 2}$ & $\mathbf{0 3}$ & $\mathbf{0 4}$ & $\mathbf{0 5}$ & $\mathbf{0 6}$ & $\mathbf{0 7}$ & $\mathbf{0 8}$ & $\mathbf{0 9}$ & $\mathbf{1 0}$ & $\mathbf{1 1}$ & $\mathbf{1 2}$ & $\mathbf{1 3}$ \\
\hline Brasil & 0,3 & 4,3 & 1,3 & 2,7 & 1,1 & 5,7 & 3,2 & 4,0 & 6,1 & 5,2 & $-0,3$ & 7,5 & 2,7 & 1,0 & 2,3 \\
Mundo & 3,7 & 4,7 & 2,3 & 2,8 & 3,8 & 5,1 & 4,7 & 5,2 & 5,3 & 2,7 & $-0,4$ & 5,2 & 3,9 & 3,2 & 3,0 \\
Emergentes & 3,7 & 5,7 & 3,8 & 4,6 & 6,3 & 7,8 & 7,3 & 8,2 & 8,7 & 5,9 & 3,1 & 7,5 & 6,3 & 5,1 & 4,7 \\
\hline
\end{tabular}

Fonte: FMI (World Economic Outlook Database, abril de 2014).

Ainda que a principal preocupação do novo regime estivesse associada ao controle inflacionário ${ }^{1}$, era notável a perspectiva de que o arcabouço lograsse maior estabilidade da atividade econômica e, a partir desta estabilidade, a retomada de taxas mais elevadas de crescimento. Como apontado pelo próprio Banco Central do Brasil (2014: 3): "há consenso na sociedade sobre as vantagens da estabilidade de preços, condição necessária para que possa haver crescimento autossustentado".

Entretanto, o novo regime apenas reforçou o resultado agonizante do país segundo esta métrica.

Diante deste quadro, dois questionamentos podem ser levantados. O primeiro relativo às causas do fenômeno do baixo crescimento no Brasil: seria possível associar a continuidade, em relação às décadas de 1980 e 1990, do fraco desempenho da atividade econômica no país à própria adoção do RMI? $\mathrm{O}$ segundo, que ajuda a explicar o primeiro, diz respeito à experiência de outros países com este regime: a subordinação do objetivo do crescimento econômico ao controle inflacionário nos países que adotaram o RMI implicou, genericamente, um desempenho menos favorável em termos daquela variável?

Esta breve nota tem por objetivo responder às duas perguntas anteriores conjuntamente. Genericamente, busca-se analisar o desempenho, em termos de crescimento econômico, dos países que adotaram o RMI como pedra fundamental

\footnotetext{
1 "A opção pelo sistema de metas para a inflação em momento de crise e incerteza refletiu uma enorme preocupação com o risco de perda de controle sobre as expectativas de inflação. Num país com nossa história de inflação, tal descontrole traria consigo a ameaça da reindexação e o pesadelo do retorno à instabilidade que existia antes do Plano Real.” (Fraga Neto, 2011: 25-6).
} 
de seu arcabouço de política econômica. Mais especificamente, busca-se avaliar se o fraco desempenho brasileiro é um caso particular ou se a implementação do RMI, genericamente, pode ser associada a resultados inferiores quanto ao crescimento econômico.

Ela está dividida em quatro partes, sendo a primeira esta introdução. A segunda seção analisa a evolução das taxas de crescimento econômico da totalidade dos países que adotaram o RMI face à economia mundial. A terceira seção reproduz essa análise dividindo a amostra entre países avançados e emergentes. A quarta seção conclui o artigo.

\section{Regime de Metas de Inflação e Crescimento: a Experiência Mundial}

A Nova Zelândia foi o primeiro país a implementar o regime de metas para inflação (RMI), o que ocorreu em dezembro de 1989, e desde então uma série de jurisdições, heterogêneas no que se refere às experiências desenvolvimento econômico, optou por adotar esta sistemática de condução da política monetária e da política econômica em geral.

Em breve definição, o RMI consiste numa estratégia de política monetária que define a estabilidade de preços como principal objetivo desta política. Metas explícitas para a evolução de um indicador de inflação são anunciadas previamente e as ações dos bancos centrais pautadas e direcionadas a esse objetivo, com a mobilização dos instrumentos correspondentes - para uma descrição mais acurada do RMI, ver Modenesi (2005: Capítulo 3) e Hammond (2012).

Em geral, neste regime, a política monetária assume um papel hierarquicamente superior às outras frentes de política econômica, em especial, a política fiscal, pautando as ações dos formuladores de política e associando a estabilidade da economia em geral à estabilidade dos preços. O crescimento econômico, nesse contexto, fica em segundo plano, sendo um subproduto da referida estabilidade.

A partir dessa caracterização, buscamos avaliar se a subordinação do objetivo do crescimento ao controle inflacionário nos países aderentes ao RMI implicou um desempenho mais fraco em termos de crescimento. Para tal, analisamos basicamente a evolução da taxa de crescimento real do PIB nos países que adotaram o RMI perante o PIB mundial, a partir dos dados da World Economic Outlook Database do Fundo Monetário Internacional (FMI).

O Gráfico 1 detalha o número de países que implementaram o referido regime. Ele permite observar a evolução positiva e a difusão dessa sistemática nos bancos centrais ao redor do mundo. Para nosso interesse momentâneo, o relevante é constatar que a amostra ganha consistência a partir de 2002, quando o número de países aderentes supera a marca dos 20, sendo que desde 2007 este número se mantém estável em 27 países. Países que adotaram o RMI e depois o desmancharam entraram e saíram da amostra nos períodos correspondentes. 
São eles Espanha e Finlândia, que desmancharam a base institucional do RMI internamente devido à adoção do Euro.

Gráfico 1: Número de Países que adotaram o RMI

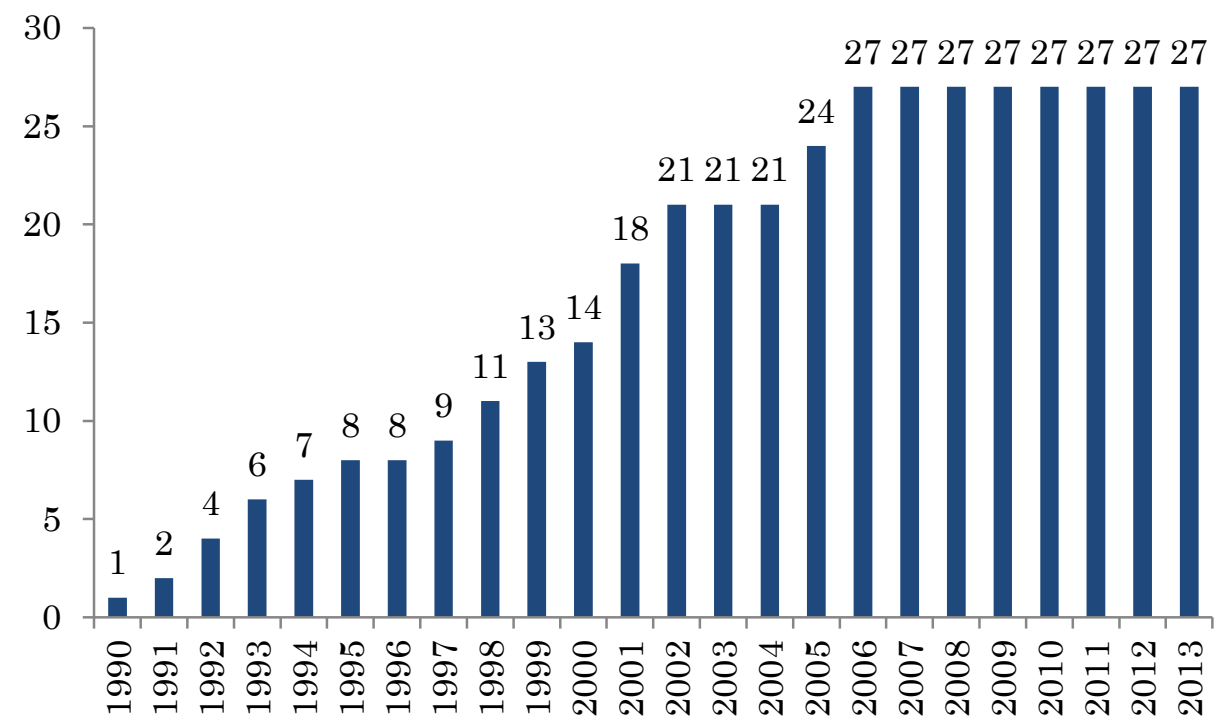

Fonte: Elaboração própria a partir de Hammond (2012).

A partir da amostra anterior, foram calculados a média e a mediana da taxa de crescimento para o conjunto de países que adotaram efetivamente o RMI, estatística que comparamos ao crescimento real do PIB mundial. O resultado é ilustrado no Gráfico 2. Desde 2002, quando temos uma amostra relevante e menos viesada pelo peso individual de cada país, podemos observar que o crescimento real do PIB dos países aderentes ao RMI não difere substancialmente do crescimento do PIB mundial.

Gráfico 2: Crescimento Real do PIB, Países Selecionados e Mundo (\% a.a.)

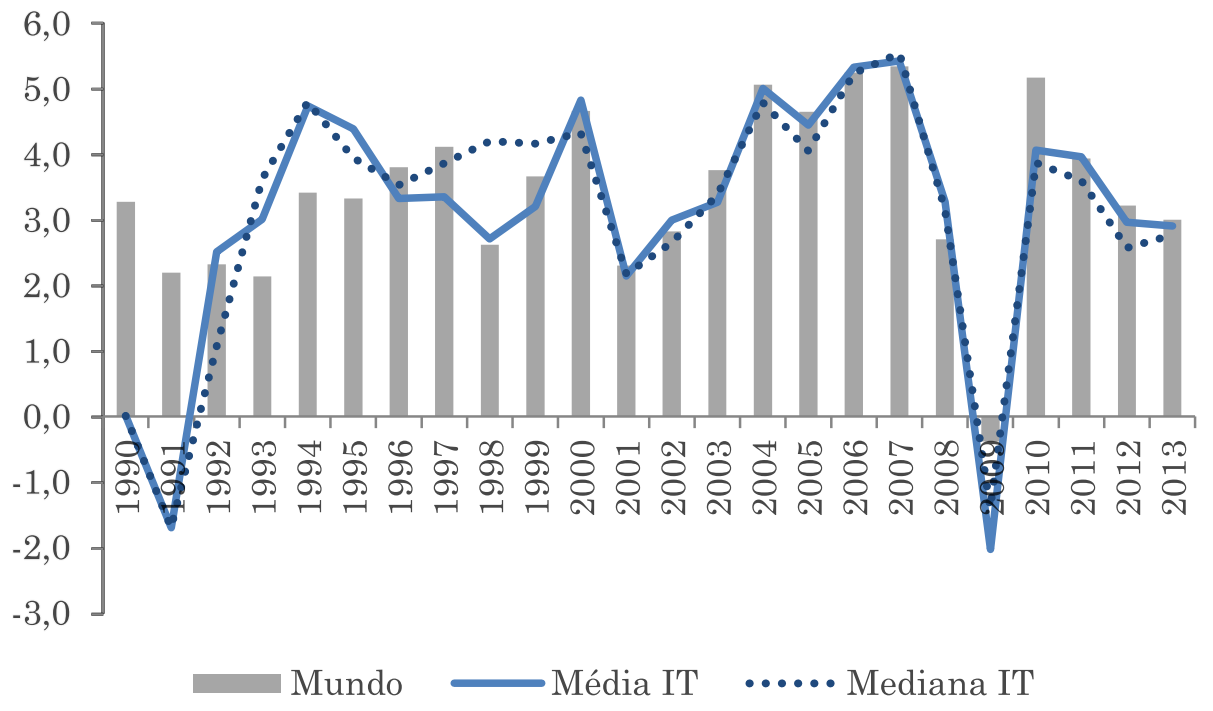

Fonte: Elaboração própria a partir de FMI (World Economic Outlook Database, abril de 2014). 
Com mais detalhe, o Gráfico 3 ilustra que, em média, o desempenho dos países aderentes ao RMI é bastante semelhante ao desempenho mundial no período 2000-2008 - a discrepância negativa de 2003 é compensada pela discrepância positiva de 2008. Já o biênio 2009-2010, marcado pela eclosão da crise financeira e sua difusão internacional, demonstra um resultado claramente inferior destes países: aparentemente, os países que utilizaram a sistemática de metas de inflação durante a crise, viram seu crescimento se reduzir mais que a média mundial.

Uma hipótese a ser levantada é que, como a redução da inflação se deu de forma defasada em relação à queda na atividade e no emprego, estes países demoraram ou foram mais conservadores na redução das taxas de juros que os demais que não aderem ao RMI. O caso brasileiro é ilustrativo, valendo lembrar a menção ao "erro de Meirelles" para se referir à elevação da taxa Selic às vésperas da quebra do banco Lehman Brothers em setembro de 2008 e sua manutenção no patamar de $13,75 \%$ até janeiro de 2009 .

Já a partir de 2011, contudo, retornamos à situação exterior de mimetismo da taxa de crescimento mundial.

\section{Gráfico 3: Diferencial entre o crescimento real do PIB dos países aderentes ao RMI e mundial (p.p.)}

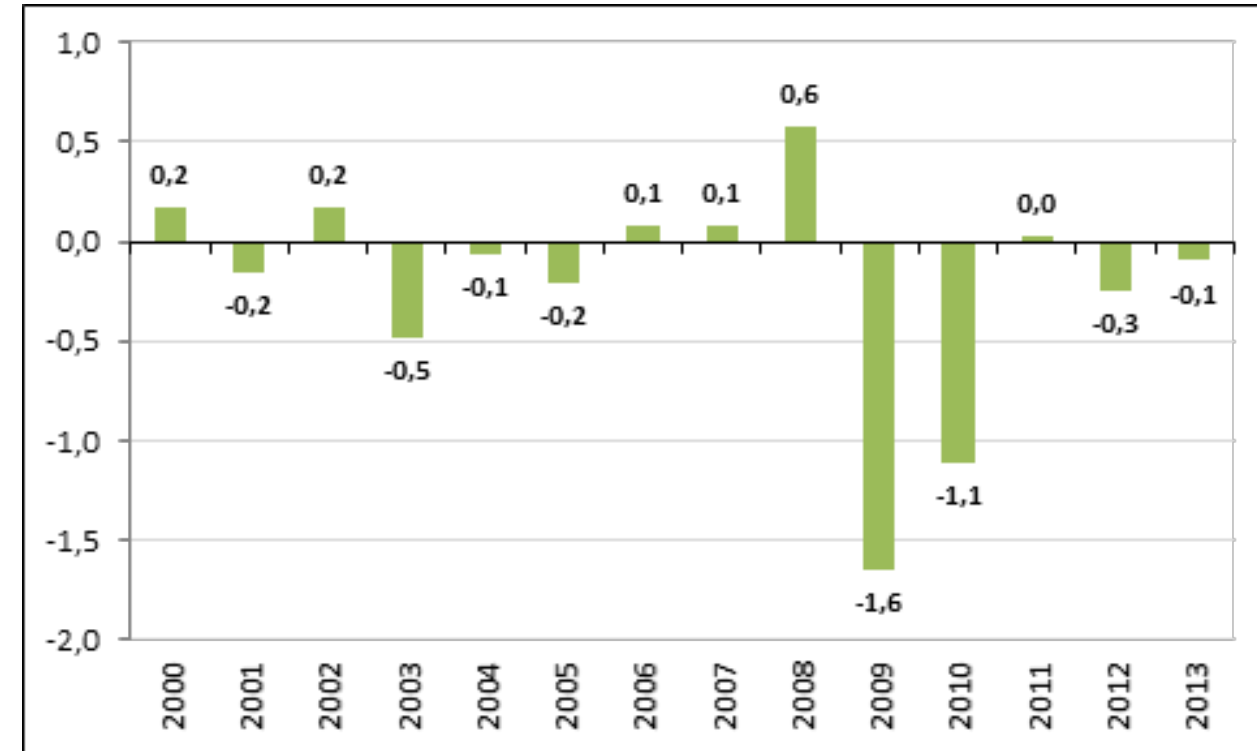

Fonte: Elaboração própria a partir de FMI (World Economic Outlook Database, abril de 2014).

Da análise deste simples indicador, podemos chegar à conclusão de que, salvo pelo biênio marcado pela crise internacional de 2008-2009, a subsunção do crescimento econômico ao controle da inflação nos países que adotaram o RMI não parece ter implicado um resultado menos favorável em termos da primeira variável: a taxa de crescimento do PIB se comportou de forma razoavelmente semelhante à média mundial.

Seria o Brasil, nesse contexto, um caso único dentre os países aderentes ao RMI? 


\section{Regime de Metas de Inflação e Crescimento: Economias Avançadas versus Emergentes}

Um exercício derivado da abordagem mais simplória da seção anterior diz respeito à separação dos países aderentes ao RMI em dois grupos: o primeiro, congregando as economias ditas avançadas; o segundo, as economias emergentes; ambos conforme a classificação sugerida pelo FMI.

Com efeito, como destacamos acima, a sistemática das metas para inflação foi adotada por jurisdições com elevado grau de heterogeneidade em termos de experiências desenvolvimento econômico. Ainda que não devamos nos restringir numa análise de desenvolvimento à dimensão da renda - no caso, da renda per capita -, esse critério de classificação permite que observemos uma característica interessante em nosso exercício.

Tabela 2 - Países aderentes ao RMI e média do crescimento real do PIB após a adesão (\% a.a.)

\begin{tabular}{lcclcc}
\hline \multicolumn{2}{c}{ Países Avançados } & \multicolumn{3}{c}{ Economia Emergentes } \\
\hline \multicolumn{1}{c}{ País } & $\begin{array}{c}\text { Ano de } \\
\text { adoção } \\
\text { do RMI }\end{array}$ & $\begin{array}{c}\text { Média } \\
\text { crescimento } \\
\text { real do PIB } \\
\text { com RMI } \\
\text { (\% a.a.) }\end{array}$ & \multicolumn{1}{c}{ País } & $\begin{array}{c}\text { Mno de } \\
\text { adoção } \\
\text { do RMI }\end{array}$ & $\begin{array}{c}\text { Mescimento } \\
\text { creal do PIB } \\
\text { rom RMI } \\
\text { (\% a.a.) }\end{array}$ \\
\hline Austrália & 1993 & 3,4 & Armênia & 2006 & 4,6 \\
Canadá & 1991 & 2,4 & Brasil & 1999 & 3,1 \\
Rep. Tcheca & 1997 & 2,3 & Chile & 1999 & 4,0 \\
Finlândia* & 1993 & 3,6 & Colômbia & 1999 & 3,7 \\
Islândia & 2001 & 2,3 & Gana & $2002 * * *$ & 6,9 \\
Israel & $1992^{* *}$ & 4,5 & Guatemala & 2005 & 3,6 \\
Coréia do Sul & 1998 & 4,0 & Hungria & 2001 & 1,6 \\
Nova Zelândia & 1989 & 2,6 & Indonésia & 2005 & 5,9 \\
Noruega & 2001 & 1,5 & México & 2001 & 2,1 \\
Espanha* & 1994 & 3,7 & Peru & 2002 & 6,3 \\
Suécia & 1995 & 2,6 & Filipinas & 2002 & 5,2 \\
Reino Unido & 1992 & 2,4 & Polônia & 1998 & 3,8 \\
& & & Romênia & 2005 & 2,7 \\
& & & Sérvia & $2006 * * * *$ & 1,6 \\
& & & Áfr. do Sul & 2000 & 3,4 \\
& & & Tailândia & 2000 & 4,1 \\
& & & Turquia & 2006 & 4,0 \\
\hline
\end{tabular}

Fonte: Elaboração própria a partir de Hammond (2012) e FMI.

* RMI desmanchado em função da adesão ao Euro.

** Informalmente; formalmente a partir de 1997.

*** Informalmente; formalmente a partir de 2007.

**** Informalmente; formalmente a partir de 2009. 
Notadamente, ao comparar a taxa de crescimento real do PIB dos países avançados que aderiram ao RMI com a média dos países avançados, podemos observar, conforme disposto no Gráfico 4, que o desempenho daqueles foi superior. Em outras palavras, a subordinação do objetivo do crescimento econômico ao combate da inflação nos países avançados que adotaram o RMI parece ter implicado uma performance não menos, porém mais favorável em termos de dinamismo da economia.

\section{Gráfico 4 - Crescimento real do PIB, Países Avançados e Países Avançados aderentes ao RMI (\% a.a.)}

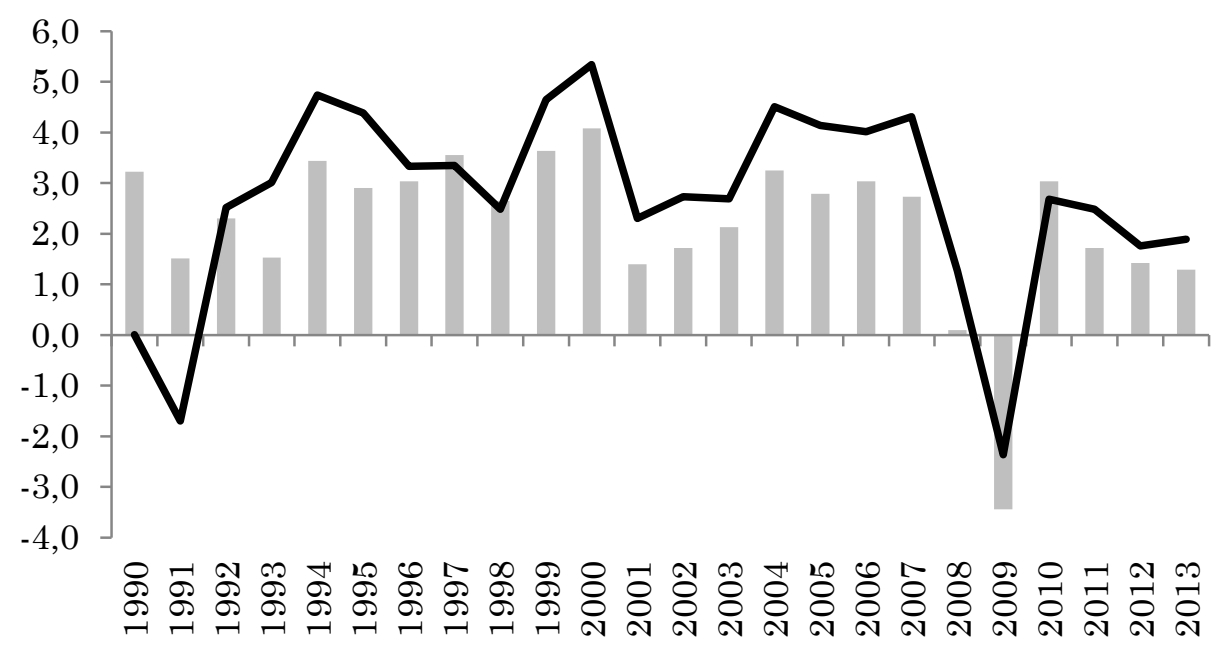

Países Avançados Países Avançados com RMI

Fonte: Elaboração própria a partir de FMI (World Economic Outlook Database, abril de 2014).

No caso dos países emergentes, entretanto, podemos observar uma situação diametralmente contrária: ao comparar a taxa de crescimento real das economias emergentes que utilizam metas para inflação com a média das economias emergentes, observamos que a performance sob o RMI é significativamente inferior, como ilustrado no Gráfico 5. Ou seja, para este conjunto de países, a subordinação do objetivo do crescimento econômico ao combate da inflação nos países avançados que adotaram o RMI parece ter implicado uma performance menos favorável em termos de dinamismo da economia. 


\section{Gráfico 5 - Crescimento real do PIB, Economias Emergentes e Economias Emergentes aderentes ao RMI (\% a.a.)}

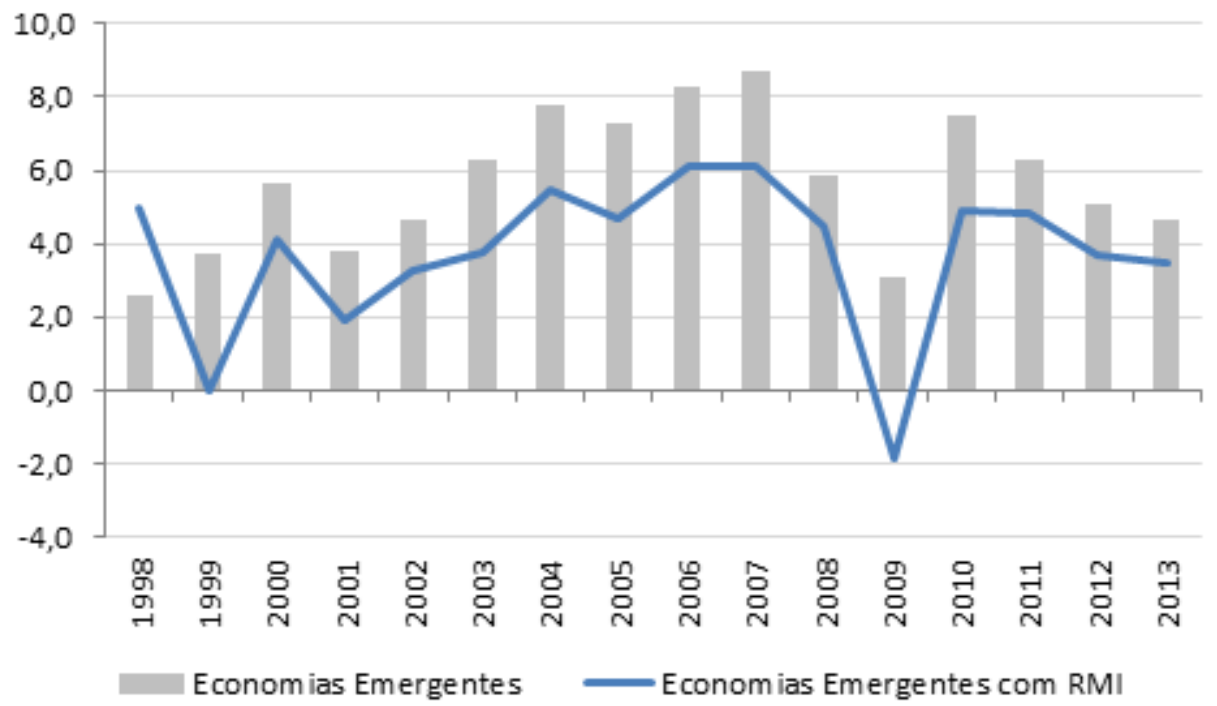

Fonte: Elaboração própria a partir de FMI (World Economic Outlook Database, abril de 2014).

O Brasil, em seu particular, não é exceção a esta (aparente) regra. Assim como outros países emergentes que adotaram o RMI, a economia brasileira cresceu abaixo da média dos países emergentes em todo período de vigência do RMI, exceto pelo ano de 2010, conforme ilustrado no Gráfico 6. Além disso, pode-se observar também que, salvo pelo biênio 2009-2010, o Brasil cresceu a taxas inferiores aos demais países emergentes que adotaram o RMI. Isso fornece evidências de que o fraco desempenho brasileiro deve ser associado não só ao regime de política econômica, mas também às idiossincrasias da nossa economia ${ }^{2}$.

Esta nota não tem como objetivo explicar essas idiossincrasias, mas tão somente pontuar o fato empírico de que após a adoção do RMI no Brasil, o país apresentou um desempenho inferior à média mundial e significativamente inferior à média dos países emergentes, destacando que essa situação parece não ser uma exclusividade brasileira, mas sim uma condição inerente a todos os países em desenvolvimento que adotaram o referido regime de política monetária.

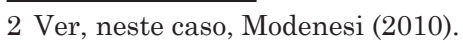




\section{Gráfico 6 - Crescimento real do PIB, Brasil, Economias Emergentes e Economias Emergentes aderentes ao RMI (\% a.a.)}

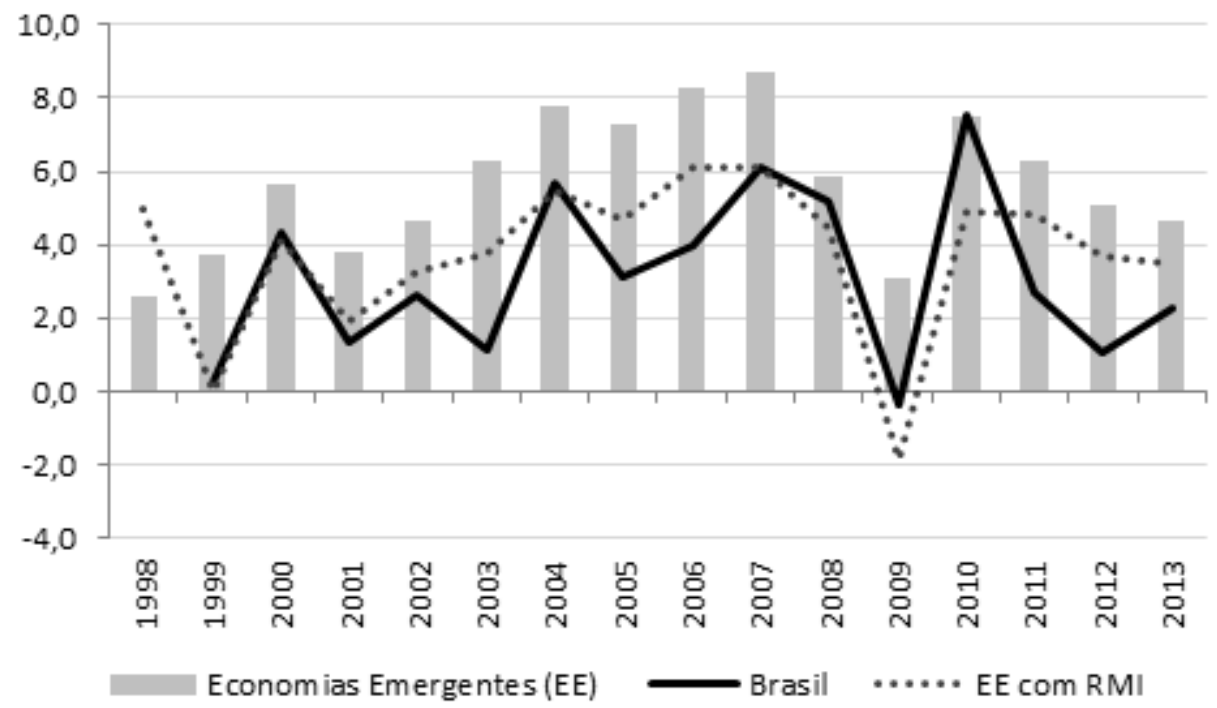

Fonte: Elaboração própria a partir de FMI (World Economic Outlook Database, abril de 2014).

\section{Conclusão}

$\mathrm{Na}$ introdução desta breve nota definimos como objetivo principal responder, conjuntamente, duas perguntas. A primeira, se seria possível associar o fraco desempenho da economia brasileira nas últimas duas décadas à adoção do RMI. A segunda, se o RMI pode ser associado genericamente a um desempenho pouco favorável em termos de crescimento econômico.

Optamos por uma análise simples dos indicadores de crescimento real do PIB dos países que adotaram o RMI perante a média mundial e a média do grupo de países desenvolvidos ou emergentes a que pertencem.

Invertendo a ordem das respostas, há evidências de que o RMI não pode ser genericamente associado a uma performance fraca em termos de crescimento econômico. Com efeito, nos países avançados, os dados analisados sugerem que essa hipótese não é verdadeira. Contudo, nos países emergentes, os dados analisados sugerem a validade da hipótese: aquelas economias emergentes que adotaram metas para inflação como guia da política monetária tiveram um desempenho significativamente inferior à média dos países emergentes.

Nesse sentido, a resposta à primeira pergunta parece ser que o fraco desempenho brasileiro nas últimas décadas pode sim ser associado à adoção do RMI, ainda que os dados analisados nos permitam constatar que, via de regra, o crescimento brasileiro foi também inferior à média dos países emergentes que adotaram o RMI. Obviamente, esse resultado deve ser relativizado, já que o exercício empírico realizado nesta nota é deveras simplório. Entretanto, constitui um ponto de partida importante para investigações futuras sobre o tema.

Por que a discrepância entre os países avançados e emergentes que 
adotaram o RMI quanto aos resultados relativos em termos de crescimento? Em particular, o que justifica o desempenho relativamente negativo dos países emergentes que adotaram o regime? Seria ele a explicação ou devemos olhar para as particularidades de cada jurisdição? Por fim, frente à evidência empírica negativa, seria apropriado a adoção do RMI nestes países? Ou seria mais razoável se estes países buscassem explorar novas experiências em termos de arranjo institucional de política monetária?

Obviamente a resposta a estas perguntas foge ao escopo desta breve nota. O mérito aqui é fixar as bases para o desenvolvimento de pesquisas futuras.

\section{Referências}

Banco Central do Brasil (2014). Regime de Metas para a Inflação no Brasil. Série Perguntas Mais Frequentes. Brasília: Banco Central do Brasil.

FMI (2014). World Economic Outlook Database. Abril de 2014. Disponível em: $<<$ http://www.imf.org/external/pubs/ft/weo/2014/01/weodata/index.aspx $>>$ (acesso em 30/01/2015).

Fraga Neto, A. (2011). "Dez Anos de Metas para a Inflação". In: Banco Central do Brasil. Dez Anos de Metas para a Inflação no Brasil: 1999-2009. Brasília: Banco Central do Brasil.

Gonçalves, R. (2014). "Balanço crítico da economia brasileira nos governos do Partido dos Trabalhadores". In: Sá Earp, F.; Bastian, E. F.; Modenesi, A. M. Como vai o Brasil?: A economia brasileira no terceiro milênio. Rio de Janeiro: Imã Editorial.

Hammond, G. (2012). State of the art of inflation targeting - 2012. Handbook - No. 29. Londres: Centre for Central Banking Studies, Bank of England.

Modenesi, A. M. (2005). Regimes Monetários: teoria e a experiência do Real. Barueri, Manole.

Modenesi, A. M. (2010). "Política Monetária no Brasil pós Plano Real (19952008): um breve retrospecto". Economia \& Tecnologia 21, Abr./Jun. 